\title{
Regression method-based analysis of damage development in the core of steel cord conveyor belts
}

\author{
Agata Kirjanów ${ }^{1, *}$ and Robert Burduk ${ }^{2}$ \\ ${ }^{1}$ Wroclaw University of Science and Technology, Faculty of Geoengineering, Mining and Geology, 27 Wyb. Wyspiańskiego St., \\ 50-370 Wroclaw, Poland \\ ${ }^{2}$ Wroclaw University of Science and Technology, Faculty of Electronics, Department of Systems and Computer Networks, 27 \\ Wyb. Wyspiańskiego St., 50-370 Wroclaw, Poland
}

\begin{abstract}
This paper is based on the data gathered with the use of the DiagBelt mobile system for non-invasive diagnostics of conveyor belts with steel-cord core. The object of the tests comprised a slow-burning ST 3150 conveyor belt, having width B-1200. The tests were performed on a belt conveyor operated in a Polish underground mine. Four tests were performed at different time intervals in order to monitor the development of conveyor belt core damage. The regression model was based on data gathered from several sections of the inspected belt and on three indicators of defects (the sum, the number and the surface of defects). The analysis was performed not only for the linear regression model, but also for the quadratic regression model, which seems to provide promising results.
\end{abstract}

\section{Introduction}

The problem of belt durability and defect identification has remained particularly important and therefore has been the object of interest for several researchers, who focused on the functional relationship between belt durability (defined as retaining its transportation function and typically expressed in terms of its operating time) and a variety of factors, including the parameters of the belt, conveyor, transported material, operating conditions etc. [1].

Steel-cord conveyor belts constitute an increasing share of the conveyor belts operated in both underground and open pit mines. They are at the same time the most expensive part of a belt conveyor, accounting for $40 \%$ to $60 \%$ of its price. During its operation, the belt is constantly exposed to detrimental effects which may significantly reduce its life-time. Even a short unplanned downtime caused by belt conveyor damage may lead to great material losses for the mining company [2]. It results not only in the interruption of the production and of the whole technological process, but frequently also in the need to purchase a new conveyor belt [3].

Early diagnosis of the damage and the ability to appropriately interpret it allow undesirable changes to be monitored and prevented before failure occurs. Application of automatic diagnostic systems in mining plants could reduce the number of situations in which the conveyor must be stopped due to failure or maintenance/inspection.

Monitoring and evaluating the technical condition of devices and machines has become an intensively developed area of research. Particular focus is placed on non-destructive testing methods (NDT). Most advantageously, this method does not compromise the strength or the structure of the inspected object. NDT methods are successfully used in many areas and in recent years they have been also widely employed in the mining industry. Earlier research in this area focused on their applications for individual elements: conveyor belts $[4,5]$, idlers [6, 7] and splices [8,9].

However, they have been also found advantageous in the diagnostics of the technical condition of belt conveyors. Research performed on this issue in a number of countries led to the development of non-destructive belt condition testing methods, which are at the heart of increasingly popular diagnostic methods. Application of such methods undoubtedly aids more precise estimations of the optimal moment for belt replacement and may prove a useful tool for predicting damage development in the belt core.

\section{Previous attempts at evaluating the condition of conveyor belt cores}

Authors of publication [10] analyzed the data on defects detected with their own NDT diagnostic tool in the cores of belt loops operated on 3 conveyors in the KWB Turów mine. These data served to identify the rate of damage density increment (the number of defects in a belt section per 1 running meter of belt) in time. Each of the analyzed conveyors was scanned twice at 15 -month intervals. The belt loops consisted of sections having various life-time, which allowed the evaluation of

\footnotetext{
* Corresponding author: agata.kirjanow@pwr.edu.pl
} 
damage increment in relation to different life-times of individual belt sections. Although the two measurements were found insufficient to evaluate individual character of damage increment (two points do not allow an accurate trajectory prediction), the authors managed to determine the character of changes for a large number of sections considered as a group. The results of research confirm that over time the damage density increment rate increases not only linearly but also according to quadratic function (e.g. a quadratic function model may be applied). Conveyor length was also found to influence the rate of damage increment, which serves as confirmation to earlier research and shows that individual selection of damage trajectory for each of the separate belt sections should lead to the best results. Similar research had never been done before.

\section{Further research into the character of damage in the conveyor belt core}

Magnetic systems have been used worldwide to inspect conveyor belts since the 1970s. Unfortunately, until recently, measurements could be performed only with measuring heads which aggregated data by scanning a width of $40 \mathrm{~cm}$ and recorded them in the form of a single channel. This approach did not allow the user to identify a single defect. An intelligent system for conveyor belt diagnostics was developed at the Machine Systems Division, Faculty of Geoengineering, Mining and Geology of the University of Science and Technology in Wroclaw, [2-4, 10]. It is shown in Fig. 1, while operated in an open pit mine.

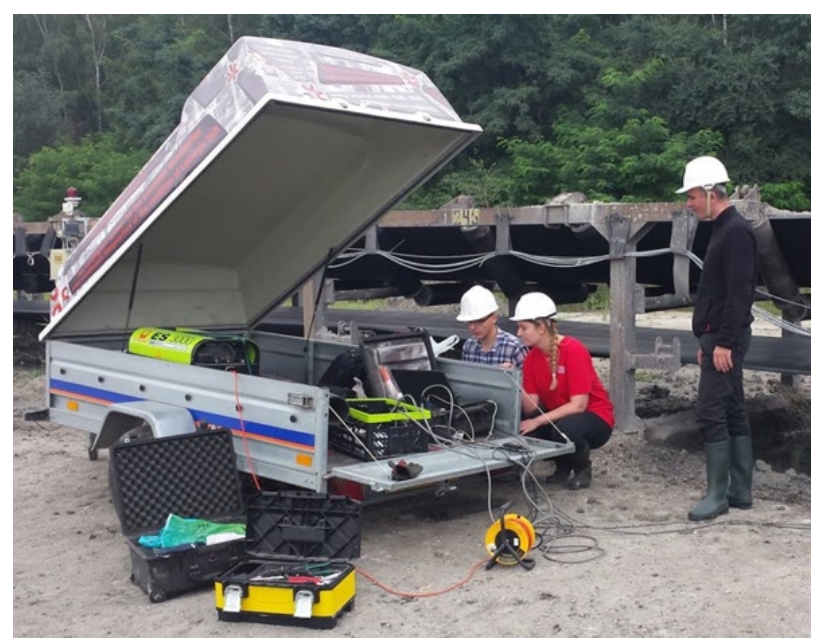

Fig. 1. The DiagBelt system during tests on a belt conveyor in an open pit mine.

One of the system's modules is a magnetic module, which operates by measuring and recording the magnetic field resulting from the discontinuation (damage) of the core's magnetized steel cords (Fig. 2).

High resolution of the measuring head allows even an individual defect in a single cord to be identified, located on the belt and measured in length and width. Fig. 3 shows a conveyor belt with a single defect and its dimensions as viewed in the DiagBelt system.

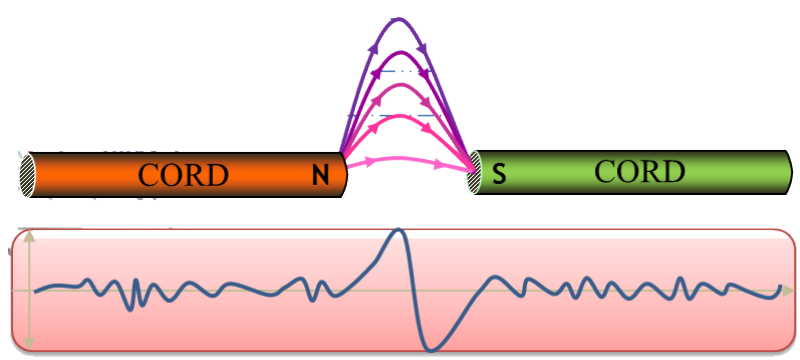

Fig. 2. Change in the magnetic field generated by the damaged steel cords in the core.

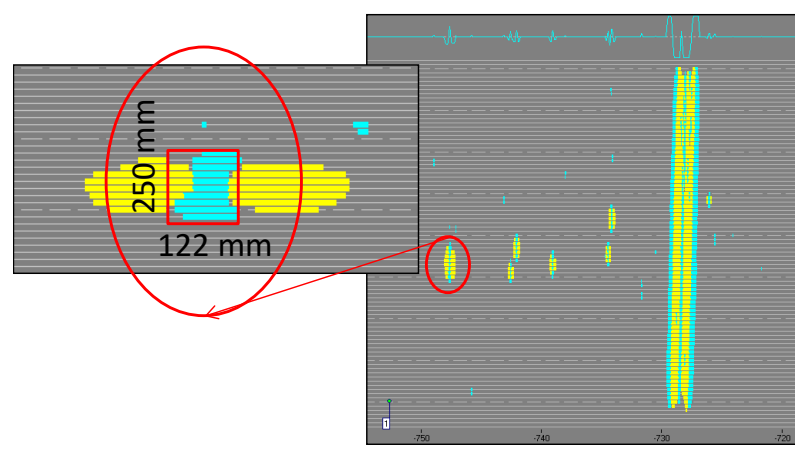

Fig. 3. Belt section with a single defect and its dimensions indicated in the DiagBelt system.

The object of the tests comprised a slow-burning ST 3150 conveyor belt, having width B-1200. The tests were performed on a belt conveyor operated in a Polish underground mine. Four tests were performed at different time intervals in order to monitor the development of conveyor belt core damage. The test location was in the vicinity of the conveyor's head station, on the belt's flat section. Two magnet heads and a measurement head were installed at a distance of $40 \mathrm{~mm}$ from the cover. Additionally, the measurement head was located over the area where the belt was supported by an idler. Thus, the influence of the belt's vertical vibration on the measurement results was minimized. Belt speed, as measured with a tachometer over the whole test, was $2.5 \mathrm{~m} / \mathrm{s}$. The data from the tachometer and from the measurement head, after being initially processed and gathered by a recorder (data acquisition module), were sent to a computer for storage. The figure below shows one of the belt's sections with an actual defect, as viewed in the DiagBelt system (Fig. 4).

Table 1 shows the number of defects, the surface areas of the damaged locations and the increment of damage both between tests and in relation to the first test performed in March 2016. Over that time, no significant or abnormal increase in the number of defects or in the size of the surface areas of core defects was observed.

Over the last period, however, the relative increase in the surface areas of the damaged locations was twice bigger than the relative increase in the number of defects, which suggests that the already existing defects grow at a similar or even greater rate than the rate at which new defects occur, since new defects usually have small size. Hence, the greatest increase in the surface area is caused by the already existent and growing defects, and not by the new ones. 


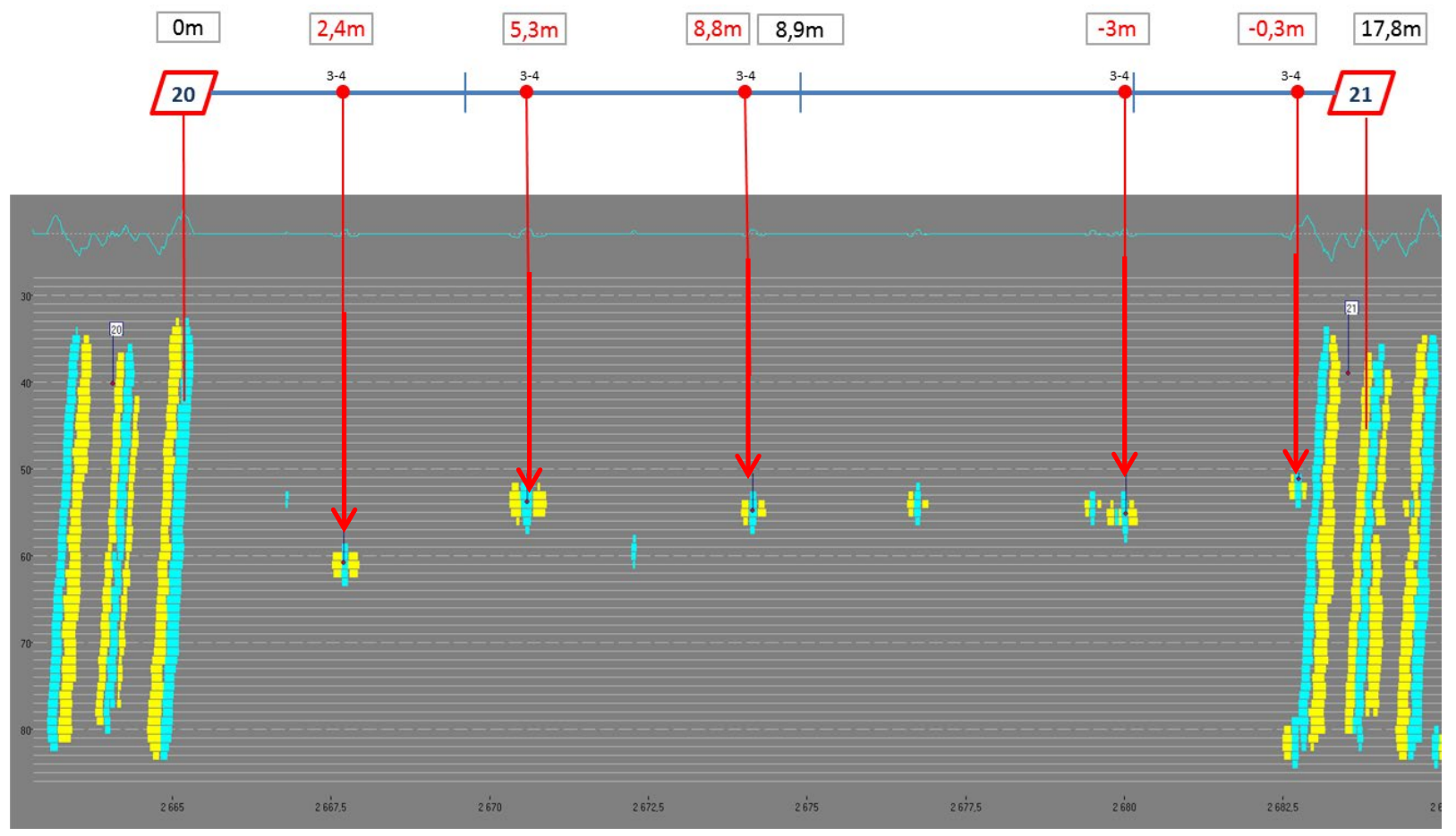

Fig. 4. A view of one of the belt's sections with an actual defect indicated.

Table 1. Increase in the number and surface area of defects between the tests.

\begin{tabular}{|c|c|c|c|c|}
\hline & $\begin{array}{l}\text { Mar. } \\
2016\end{array}$ & $\begin{array}{l}\text { Sept. } \\
2016\end{array}$ & \multicolumn{2}{|c|}{ Dec. 2016} \\
\hline Number of defects & 3624 & 4414 & \multicolumn{2}{|c|}{4826} \\
\hline $\begin{array}{c}\text { Increase of defect } \\
\text { number } \\
*_{\text {-as of } 03.2016} \\
*_{*} \text {-as of } 09.2016\end{array}$ & \multicolumn{2}{|c|}{$21.80 \%$} & $9.33 \%$ & $\begin{array}{c}33.17 \\
\%\end{array}$ \\
\hline $\begin{array}{l}\text { Total surface area } \\
\text { of all defects }\left[\mathrm{m}^{2}\right]\end{array}$ & 36.6 & 49.06 & \multicolumn{2}{|c|}{57.59} \\
\hline $\begin{array}{c}\text { Increase in the } \\
\text { surface area of the } \\
\text { defects }[\%]\end{array}$ & \multicolumn{2}{|c|}{$34.04 \%$} & $\begin{array}{c}17.39 \\
\%\end{array}$ & $\begin{array}{c}57.35 \\
\%\end{array}$ \\
\hline
\end{tabular}

\section{Prediction methods in the analysis of belt core damage}

In order to predict belt core damage, linear and quadratic regression was used. Time, defined as the number of quarters of a year during which the belt was operated, was selected as the independent random variable. The choice of quarters of a year as a measure of time intervals was dictated by the frequency of conveyor belt diagnostic procedures. Dependent random variables included "the sum of defects," "the number of defects," or "the surface of defects." Experimental tests aimed at determining the applicability of different regression models were based on two scenarios. In the first scenario, the belt's original condition was allowed for, and the values of both the independent random variable and all dependent random variables were assumed at 0 (quarter 0 and no belt damage, respectively). In the second scenario, the belt's original condition was not allowed for. Regression curves were calculated individually for three belt sections which were operated without repairs throughout the whole test period. Thus, each of the belt sections (designated as section 2, section 10 and section 22) was used to calculate and evaluate the accuracy of damage prediction individually for each section. Tables 2-4 contain the measured values for section 2, 22 and 10 in successive periods of time, as well as the values of the number of defects together with the values predicted by the model and verified in successive measurements.

Prediction of the value of the sum, the number and the surface of defects in the first scenario was based on the first two observations and with allowance for no damage in the newly installed belt, which means that the model was in fact based on three observations. In the second scenario, the model was based only on the measurements of the operated belt, without the observation " 0 " for the newly installed belt.

\section{Conclusions}

In this paper, the DiagBelt system has been used to acquire data regarding the belt defects and two regression method was used to prediction damage of the belt with steel-cord core. The paper presents data and obtained results from three randomly selected sections (labeled as 2, 10 and 22) of a conveyor belt.

Based on randomly selected belt sections, a conclusion may be formulated that linear regression models allow a more accurate estimation of the number, sum and surface of conveyor belt defects. The estimated values of the defect number are mostly understated for the period of time associated with the last measurement. 
Table 2. Model fitting - defect number for section 2.

\begin{tabular}{|c|c|c|c|c|c|c|c|c|c|}
\hline \multicolumn{6}{|c|}{ Defect sum for section 22} & \multicolumn{4}{|c|}{ Model fitting } \\
\hline & & \multicolumn{2}{|c|}{ With observation " 0 " } & \multicolumn{2}{|c|}{$\begin{array}{l}\text { Without observation } \\
\text { "0" }\end{array}$} & \multicolumn{2}{|c|}{ With observation “0” } & \multicolumn{2}{|c|}{ Without observation " 0 " } \\
\hline Time & Measured & $\begin{array}{c}\text { Linear } \\
\text { regression }\end{array}$ & $\begin{array}{l}\text { Quadratic } \\
\text { regression }\end{array}$ & $\begin{array}{l}\text { Linear } \\
\text { regression }\end{array}$ & $\begin{array}{l}\text { Quadratic } \\
\text { regression }\end{array}$ & $\begin{array}{l}\text { Linear } \\
\text { regression }\end{array}$ & $\begin{array}{l}\text { Quadratic } \\
\text { regression }\end{array}$ & $\begin{array}{c}\text { Linear } \\
\text { regression }\end{array}$ & $\begin{array}{l}\text { Quadratic } \\
\text { regression }\end{array}$ \\
\hline 1 & 0 & $-0,01$ & 0,00 & 0 & 0 & 0 & 0 & 0 & 0 \\
\hline 19 & 0,74 & 0,83 & 0,74 & 0,74 & 0,74 & 0,007985 & 0,000008 & 0,000002 & $1,3 \mathrm{E}-14$ \\
\hline 21 & 0,94 & 0,92 & 0,93 & 0,94 & 0,94 & 0,000294 & 0,000060 & 0,000019 & $2,0 \mathrm{E}-14$ \\
\hline 22 & 1,03 & 0,97 & 1,03 & 1,03 & 1,03 & 0,003651 & 0,000024 & 0,000008 & $2,4 \mathrm{E}-14$ \\
\hline 26 & 1,2 & 1,16 & 1,50 & 1,42 & 1,32 & 0,001889 & 0,089464 & 0,048996 & 0,015 \\
\hline \multicolumn{6}{|c|}{ Sum of squares } & 0,003 & 0,022 & 0,012 & 0,004 \\
\hline
\end{tabular}

Table 3. Model fitting - defect number for section 22 .

\begin{tabular}{|c|c|c|c|c|c|c|c|c|c|}
\hline \multicolumn{6}{|c|}{ Defect number for section 22} & \multicolumn{4}{|c|}{ Model fitting } \\
\hline & & \multicolumn{2}{|c|}{ With observation "0" } & \multicolumn{2}{|c|}{$\begin{array}{c}\text { Without observation } \\
\text { " } 0 "\end{array}$} & \multicolumn{2}{|c|}{ With observation " 0 " } & \multicolumn{2}{|c|}{ Without observation " 0 " } \\
\hline Time & Measured & $\begin{array}{c}\text { Linear } \\
\text { regression }\end{array}$ & $\begin{array}{l}\text { Quadratic } \\
\text { regression }\end{array}$ & $\begin{array}{c}\text { Linear } \\
\text { regression }\end{array}$ & $\begin{array}{l}\text { Quadratic } \\
\text { regression }\end{array}$ & $\begin{array}{c}\text { Linear } \\
\text { regression }\end{array}$ & $\begin{array}{l}\text { Quadratic } \\
\text { regression }\end{array}$ & $\begin{array}{c}\text { Linear } \\
\text { regression }\end{array}$ & $\begin{array}{l}\text { Quadratic } \\
\text { regression }\end{array}$ \\
\hline 1 & 0 & -0.01 & 0 & 0 & 0 & 0 & 0 & 0 & 0 \\
\hline 19 & 0.87 & 0.92 & 0.87 & 0.87 & 0.87 & 0,002812 & 0,000001 & 0,000002 & 0,0 \\
\hline 21 & 1.03 & 1.03 & 1.03 & 1.03 & 1.03 & 0,000013 & 0,000005 & 0,000019 & 0,0 \\
\hline 22 & 1.12 & 1.08 & 1.12 & 1.12 & 1.12 & 0,001756 & 0,000002 & 0,000008 & 0,0 \\
\hline 26 & 1.38 & 1.28 & 1.5 & 1.45 & 1.55 & 0,009052 & 0,013846 & 0,004713 & 0,027778 \\
\hline \multicolumn{6}{|c|}{ Sum of squares } & 0,003 & 0,003 & 0,001 & 0,007 \\
\hline
\end{tabular}

Table 4. Model fitting - defect number for section 10 .

\begin{tabular}{|c|c|c|c|c|c|c|c|c|c|}
\hline \multicolumn{6}{|c|}{ Defect surface for section 22} & \multicolumn{4}{|c|}{ Model fitting } \\
\hline & & \multicolumn{2}{|c|}{ With observation "0" } & \multicolumn{2}{|c|}{$\begin{array}{l}\text { Without observation } \\
\text { "0" }\end{array}$} & \multicolumn{2}{|c|}{ With observation " 0 " } & \multicolumn{2}{|c|}{ Without observation " 0 " } \\
\hline Time & Measured & $\begin{array}{l}\text { Linear } \\
\text { regression }\end{array}$ & $\begin{array}{l}\text { Quadratic } \\
\text { regression }\end{array}$ & $\begin{array}{l}\text { Linear } \\
\text { regression }\end{array}$ & $\begin{array}{l}\text { Quadratic } \\
\text { regression }\end{array}$ & $\begin{array}{c}\text { Linear } \\
\text { regression }\end{array}$ & $\begin{array}{l}\text { Quadratic } \\
\text { regression }\end{array}$ & $\begin{array}{l}\text { Linear } \\
\text { regression }\end{array}$ & $\begin{array}{l}\text { Quadratic } \\
\text { regression }\end{array}$ \\
\hline 1 & 0 & $-0,005$ & 0,003 & 0 & 0 & 0 & 0 & 0 & 0 \\
\hline 19 & 1,01 & 1,054 & 1,979 & 1,014 & 1,010 & 0,002 & 0,940 & 0,00002 & 0,0 \\
\hline 21 & 1,19 & 1,171 & 2,353 & 1,177 & 1,190 & 0,000 & 1,353 & 0,00016 & 0,0 \\
\hline 22 & 1,25 & 1,230 & 2,552 & 1,259 & 1,250 & 0,000 & 1,694 & 0,00007 & 0,0 \\
\hline 26 & 1,36 & 1,466 & 3,423 & 1,584 & 1,290 & 0,011 & 4,254 & 0,05032 & 0,00490 \\
\hline \multicolumn{6}{|c|}{ Sum of squares } & 0,003 & 2,060 & 0,013 & 0,001 \\
\hline
\end{tabular}

However, the quadratic regression model overstates the corresponding values.

Further research will focus on developing a hybrid model intended to eliminate both the underestimations of defect numbers in models allowing for observation « $0 »$ and the overestimations in models not allowing for observation « 0 ». The model can be a helpful tool for an economically justified moment of dismantling the conveyor belt in the mines. Improving the model on more data on different conveyor belts will enable the implementation of the developed algorithm for the DiagBelt system.

This paper was financially supported by statutory activity, No: 0402/0010/17

\section{References}

1. T. Żur, Górnictwo Odkrywkowe, 1 (1975, in Polish)

2. R. Blazej, L. Jurdziak, W. Kawalec, Lecture Notes in Engineering and Computer Science, 2217, 557561 (2015)

3. L. Jurdziak and R. Zimroz, Prace Naukowe Instytutu Górnictwa Politechniki Wrocławskiej, 106 (2004)

4. M. Bajda, R. Blazej, L. Jurdziak, Mining Science, 23, 173-182 (2016)

5. R. Król, W. Kisielewski, D. Kaszuba, L. Gładysiewicz, International Journal of Mining, Reclamation and Environment, 31(1), 78-90 (2017)

6. L. Gładysiewicz, W. Kawalec, R. Król, Eksploatacja i Niezawodność, 18(1), 32-37 (2016)

7. R. Król, W. Kisielewski, D. Kaszuba, L. Gładysiewicz, Procedia: Earth and Planetary Science 2015, 15, 712-719 (2015) 
8. M. Hardygóra, H. Komander, R. Błazej, L. Jurdziak, Eksploatacja i Niezawodność, 14, 2, 171-175 (2012)

9. R. Błażej and M. Hardygóra, Bulk Solids Handling, 23, 4, 234-241 (2003)

10. R. Błażej, L. Jurdziak, R. Zimroz, Górnictwo i Geoinżynieria, R. 35, z. 3/1, 63-71 (2011) 